\title{
NARRATIVAS TRANSMÍDIA APLICADAS À EDUCAÇÃO: UMA ANÁLISE DO PROJETO MULTIPLATAFORMA "HORA DO ENEM".
}

\section{TRANSMEDIA IN EDUCATION: REVIEW OF MULTIMEDIA PROJECT "HORA DO ENEM"}

Leonardo Enrico Schimmelpfeng ${ }^{1}$, M.Sc.

(1) Universidade Federal de Santa Catarina (UFSC)

e-mail: leoenricos@gmail.com

Luciane Maria Fadel ${ }^{2}$, D.Sc.

(2) Universidade Federal de Santa Catarina (UFSC)

e-mail: liefadel@gmail.com -

Vania Ribas Ulbricht ${ }^{3}$, D.Sc.

(3) Universidade Federal de Santa Catarina (UFSC)

e-mail: vrulbricht@gmail.com

Palavras chave: narrativas transmídia, educação virtual, projeto Hora do Enem

A partir do surgimento das novas TICs e dos conceitos de Sociedade da Conhecimento e da Sociedade da Informação, surgem também novas mudanças no processo educacional, modelos de ensino e processos de aprendizagem. Essas novas construções podem ser mediada pela tecnologia e suas diferentes mídias e plataformas. A partir dos conceitos de narrativas transmídia; micronarrativas, storyworlds, e das possibilidades de maior imersão dos fãs nas narrativas, este trabalho realizou a análise de aplicação dessas propostas transmídia no portal "Hora do Enem", verificando como os conceitos citados podem ser encontrados em projetos de educação virtual.

Keywords: Transmedia, virtual learning, Hora do Enem project

With the new technologies of information and communication and the concepts of Knowledge Society and Information Society, new changes in the educational process, teaching models and learning processes begin. These new constructions can be mediated by technology and its different media and platforms. From the concepts of transmedia, micronarratives, and possibilities of fan immersion in the narratives, this work carried out the analysis of the application of these transmidia proposals in the website "Hora do Enem", checking how concepts can be found in virtual education projects. 
$16^{\circ}$ Ergodesign - Congresso Internacional de Ergonomia e Usabilidade de Interfaces Humano Tecnológica: Produto, Informações Ambientes Construídos e Transporte

$16^{\circ}$ USIHC - Congresso Internacional de Ergonomia e Usabilidade de Interfaces Humano Computador

CINAHPA | 2017 - Congresso Internacional de Ambientes Hipermídia para Aprendizagem.

\section{Introdução}

Com a popularização das novas Tecnologias da Informação e Comunicação (TICs) e a imersão da sociedade aos meios tecnológicos surgidos com as mídias digitais, inaugurou-se um novo momento (ainda em construção) no qual mudanças em diferentes instâncias (sociais, políticas, culturais, educacionais) têm sido mediadas pela tecnologia.

Nesse contexto, a educação também torna-se objeto de estudo para que ela absorva os recursos das novas tecnologias, nas quais os estudos e discussões sobre a inserção dos meios digitais no processo educativo passam a ser cada vez mais utilizados em questionamentos da chamada educação tradicional.

Em relação ao conhecimento, Bernheim (2008), afirma que o que tem sido chamado de explosão do conhecimento é um fenômeno tanto quantitativo quanto qualitativo, no sentido de que o volume de conhecimento disciplinar aumenta de maneira progressiva. E para além da progressão qualiquantitativa apresentada e questionada pelo pesquisador - na qual o modelo de educação tradicional tem mostrado diversas fragilidades em relação à incorporação das mídias digitais aos processos de ensino-aprendizagem - surgem também novas propostas para tentar agregar aos modelos de ensino o uso das novas tecnologias, mídias e plataformas digitais.

[Morin, 1999], se vale das tecnologias para questionar o modelo de educação tradicional, inserindo a educação em seus conceitos do pensamento complexo. $\mathrm{O}$ autor afirma que a supremacia de um conhecimento fragmentado segundo as disciplinas, muitas vezes nos incapacita de vincular as partes e o todo, e este deveria ser substituído por um modo de conhecimento capaz de apreender os objetos nos seus contextos, nas suas complexidades, na sua totalidade._Assim, os aspectos da inclusão digital e da democratização da informação adquirem novas reflexões, nos quais não basta o acesso às tecnologias, às redes virtuais e a internet: há também a necessidade de se entender como utilizá-la a favor do conhecimento.
Com base no apresentado, esse trabalho analisa como o projeto "Hora do Enem", construído com uma linguagem multiplataforma, utiliza-se de estratégias transmídia para incorporação das mídias digitais aos processos de ensino aprendizagem. Ao explorar essa incorporação, iremos verificar também se existem ou não a utilização de pontes narrativas e interrelações entre conteúdos educativos, uma das características das narrativas transmídia e que, no caso de conteúdos educativos, pode promover dinamismo, maior imersão e facilitar a interação e compartilhamento dos conteúdos.

Nessa perspectiva surgem conceitos como o letramento digital, que segundo [Gallo e Coelho, 2012], se alinham ao surgimento ou adaptação das práticas socioculturais, por meio da apropriação de novos signos e linguagens, artefatos tecnológicos e processos comunicacionais para, efetivamente, promover uma participação efetiva na chamada Sociedade do Conhecimento, seja consumindo ou produzindo informação para gerar conhecimento.

\section{Narrativas transmídia}

Uma das estratégias que se pluralizaram com as mídias digitais foram as narrativas transmídia. [Jenkins, 2009], determina o conceito de narrativa transmídia como a produção de conteúdos a partir de uma "nova estética que surgiu em resposta à convergência das mídias - uma estética que faz novas exigências aos consumidores e depende da participação ativa de comunidades de conhecimento". Em seu livro Cultura da convergência, ele afirma que, "a narrativa transmídia é a arte da criação de um universo". Para viver uma experiência plena num universo ficcional, os consumidores devem assumir o papel de caçadores e coletores, perseguindo pedaços da história pelos diferentes canais, comparando suas observações com as de outros fãs, em grupos de discussão online, e colaborando para assegurar que todos os que investiram tempo e energia tenham uma experiência de entretenimento mais rica.

Assim, uma história transmídia se desenvolve através de múltiplos suportes midiáticos, com diversos novos textos surgindo (seja ele distribuído 


\section{$16^{\circ}$ \\ ERGODESIGN USIHC CINAHPA}

$16^{\circ}$ Ergodesign - Congresso Internacional de Ergonomia e Usabilidade de Interfaces Humano Tecnológica: Produto, Informações Ambientes Construídos e Transporte

$16^{\circ}$ USIHC - Congresso Internacional de Ergonomia e Usabilidade de Interfaces Humano Computador

CINAHPA | 2017 - Congresso Internacional de Ambientes Hipermídia para Aprendizagem. pelos produtores dos conteúdos ou pelos fãs dessas histórias), o que traz uma contribuição diferente e valiosa para o todo. Elas tem a característica de serem exploradas em multiplataformas (como em um filme, ser expandida para a televisão, novelas e HQ; games, webséries e outras possibilidades.

Os universos são expandidos para além da narrativa principal, proporcionando novas experiências com a história e, a possibilidade de interação entre o fã e o universo da narrativa. Cada produto atua como um universo que expande e adiciona elementos às narrativas, permitindo uma imersão ainda maior do fã. Essas narrativas podem também funcionar de maneira independente: não há uma necessidade inerente de se ter consumido uma obra para compreender a outra.

\section{Revisão bibliográfica}

Em um universo que utiliza de construções narrativas, direcionadas para conhecimento e produção de conteúdos, as estratégias de narrativas transmídia podem ser aplicadas à educação. [Scolari, 2014], pontua sobre a utilização das narrativas transmídia nos meios educativos. Segundo o autor, "as práticas transmídia estão mudando os caminhos das análises de pesquisadores e educadores: a alfabetização midiática não pode ser limitada a uma análise crítica da produção ou a linguagem dos meios de comunicação. O antigo consumidor de mídia é agora um prosumer (produtor + consumidor ), um sujeito ativo que cria novos conteúdos e os compartilha nas redes digitais".

Para além de uma abordagem diferenciada em relação à produção de conteúdos, Scolari, aborda sobre como a educação também precisa ser atingida pelo conceito de prosumer [Jenkins, 2009], articulando a utilização das plataformas e narrativas transmidiáticas para promover experiências do universo de fãs, como a criação e o compartilhamento de conteúdos a partir do universo educativo presente na rede. [Jenkins, 2012], também compartilha dessa visão. No artigo "Lendo criticamente e lendo criativamente", o pesquisador pontua que "as escolas têm, historicamente, ensinado os estudantes a ler com o objetivo de produzir uma resposta crítica (...) queremos encorajar educadores a também ensinar aos alunos como se engajar criativamente com textos". O pesquisador ainda aponta que a leitura das mídias deve ser realizada de maneira crítica e criativa, podendo se utilizar da Sociedade da Informação, como base para reagir e recriar o que está disponível.

Se os conceitos de mobilidade, interatividade, colaboração e compartilhamento são tônicas das narrativas transmídia, eles também se constroem nas mídias digitais, por meio das redes sociais. Mas como essa dinâmica pode ser levada para a educação virtual?

A pergunta não tem um resposta simples: um primeiro fator limitante se deve ao fato de que as narrativas transmídia emergem e se popularizam em multiplataformas - as quais o a maioria dos processos educacionais ainda não explora de maneira eficaz.

Muitos autores tem trabalhado com pontes narrativas de imersão aos conteúdos educativos, como o proposto por [Gerbasi, 2006], com a utilização de vídeos dinâmicos, realizados a partir das técnicas da produção audiovisual televisiva e cinematográfica; estratégias de narrativas gamificadas, com "certos dispositivos de controle da narrativa, distribuídas através de micronarrativas e espaços do jogo", [Jenkins, 2012]; os storyworlds, interfaces narrativas e micronarrativas, de [Bizzocchi, 2014]; os conceitos por [Petrovic e Ivetic, 2012] - que mapearam métricas de satisfação de usuários de games e as relacionam com a educação virtual ou, [Alves, 2012] e [McGonigal, 2011], que propõe recomendações para o uso da gamificação em objetos de aprendizagem.

Modifica-se o processo de organização das narrativas nas mídias digitais (e, por consequência, da educação virtual - principalmente se aplicadas às plataformas virtuais de educação, permitindo que os cursos se tornem mais atrativos, dinâmicos, baseados em recursos e estratégias das mídias digitais), estimulando a interação e o compartilhamento do conhecimento. 


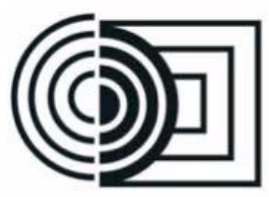

$16^{\circ}$ Ergodesign - Congresso Internacional de Ergonomia e Usabilidade de Interfaces Humano Tecnológica: Produto, Informações Ambientes Construídos e Transporte

$16^{\circ}$ USIHC - Congresso Internacional de Ergonomia e Usabilidade de Interfaces Humano Computador

CINAHPA | 2017 - Congresso Internacional de Ambientes Hipermídia para Aprendizagem.
Esse universo educacional narrativo e imersivo pode seguir diferentes propostas. $\mathrm{O}$ aluno pode, por exemplo, iniciar o processo a partir de uma vídeoaula dinâmica; ir se aprofundando nos conhecimentos de maneira voluntária, com outros conteúdos como textos, hiperlinks de materiais disponíveis na rede; redes sociais; objetos de aprendizagem gamificados; dentre outras possibilidades.

Para verificar a aplicação de algumas das estratégias transmídia, este trabalho analisa o projeto Hora do Enem - uma iniciativa do Governo Federal e Ministério da Educação (MEC) que construiu um portal com conteúdos de estudos voltados para o Exame Nacional do Ensino Médio (Enem), disponibilizados em multiplataformas.

As estratégias de divulgação do projeto propagam a ideia de que os alunos podem construir de maneira personalizada sua trajetória de estudos e que os conteúdos são organizados de maneira complementares (permitindo uma associação das estratégias transmídia como a construção de pontes e narrativas que se complementam; estímulo da interação e construção das narrativas em diferentes plataformas).

A proposta deste trabalho é verificar como o projeto utiliza estratégias transmídia em sua produção multiplataforma, baseada em um modelo não tradicional do processo de ensinoaprendizagem, focado nas mídias digitais e no compartilhamento do conhecimento.

\section{Objeto de analise}

O objeto de análise desse trabalho é o projeto Hora do Enem, desenvolvido para mediar e facilitar os estudos dos alunos candidatos ao Exame Nacional do Ensino Médio (Enem). Segundo o Inep, o conteúdo das provas do Enem é definido a partir de matrizes de referência em quatro áreas do conhecimento:

- Linguagens, códigos e suas tecnologias, que abrange o conteúdo de Língua Portuguesa (Gramática e Interpretação de Texto), Língua Estrangeira Moderna,
Literatura, Artes, Educação Física e Tecnologias da Informação.

- Matemática e suas tecnologias.

- Ciências da Natureza e suas tecnologias, que abrange os conteúdos de Química, Física e Biologia.

- Ciências Humanas e suas tecnologias, que abrange os conteúdos de Geografia, História, Filosofia, Sociologia e conhecimentos gerais.

No portal Hora do Enem, o estudante tem a possibilidade de personalizar a sua plataforma de estudos de acordo com o seu perfil. Além disso é possível acompanhar o programa de TV (na TV ou na internet), fazer simulados on-line, criar planos de estudos personalizados, assistir vídeos de temas específicos, receber newsletters, acessar questões comentadas, conhecer estudantes e interagir com eles. A figura 1 mostra como os conteúdos se articulam de maneira integrada para que os alunos possam personalizar seu trajeto de estudo:

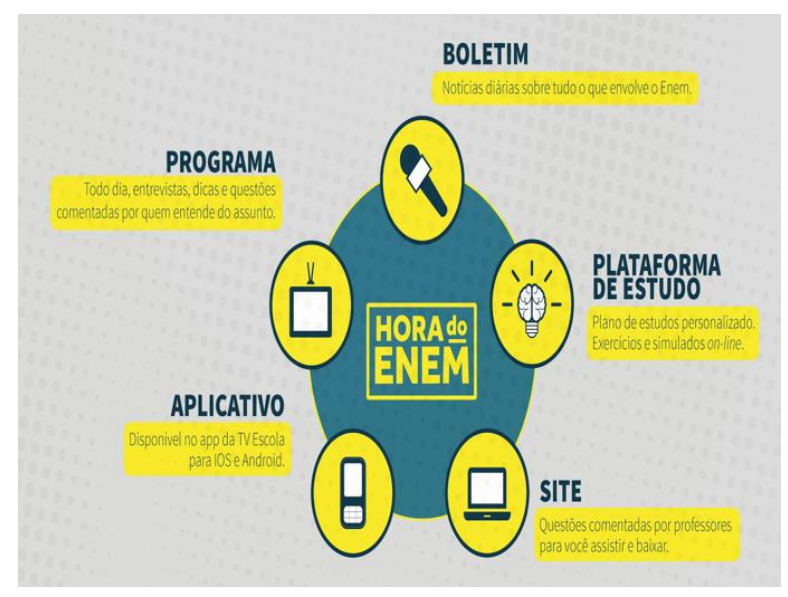

Figura 1 - os diferentes conteúdos educativos disponibilizados no projeto Hora do Enem.

Fonte: www.horadoenem.mec.gov.br. Acesso em 27 nov 2016.

A partir de informações colhidas no site, apresentamos cada uma das diferentes propostas de conteúdo e estratégias de abordagem do projeto.

Programa de TV
Realização:

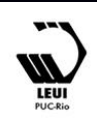




\section{$16^{\circ}$ \\ ERGODESIGN USIHC CINAHPA}

O programa hora do Enem tem 30 minutos de duração e exibição diária no canal TV Escola. Os programas já exibidos também estão disponíveis sob demanda ou para download no site do projeto. No primeiro e no segundo blocos, o programa apresenta informações gerais sobre o ENEM orientações, e comenta questões dos anos anteriores. No terceiro bloco, um convidado é recebido, para ampliar a discussão do Enem para além dos conteúdos trabalhados nas provas. Os temas de cada dia da semana estão disponíveis no site do projeto, como mostra a figura 2 :

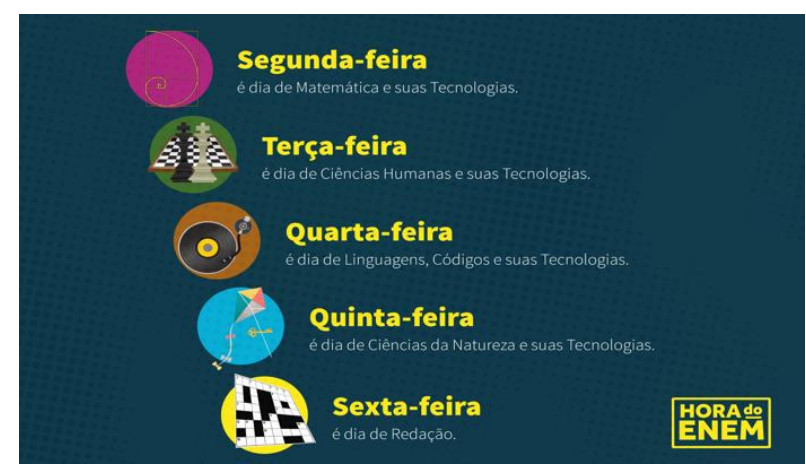

Figura 2 - Dias de apresentação do programa no canal TV Escola.

Fonte: www.horadoenem.mec.gov.br. Acesso em 27 nov 2016.

\section{Plataforma de Estudo}

A plataforma de estudos foi desenvolvida para que os alunos possam utilizar os conteúdos de estudo disponibilizados no projeto para elaborar um plano de estudos de acordo com o seu perfil, tendo acesso a videoaulas, exercícios e simulados. Após os primeiros testes, o aluno recebe uma trilha de estudos para seguir. Por meio dos estudos, solução de exercícios e simulados, o desempenho do aluno na plataforma o auxilia a modificar e readequar metas e o plano de ensino, de maneira automatizada. A figura 3 mostra como são feitas as escolhas para elaborar o plano de estudos personalizados: $16^{\circ}$ Ergodesign - Congresso Internacional de Ergonomia e Usabilidade de Interfaces Humano Tecnológica: Produto, Informações Ambientes Construídos e Transporte

$16^{\circ}$ USIHC - Congresso Internacional de Ergonomia e Usabilidade de Interfaces Humano Computador

CINAHPA | 2017 - Congresso Internacional de Ambientes Hipermídia para Aprendizagem.

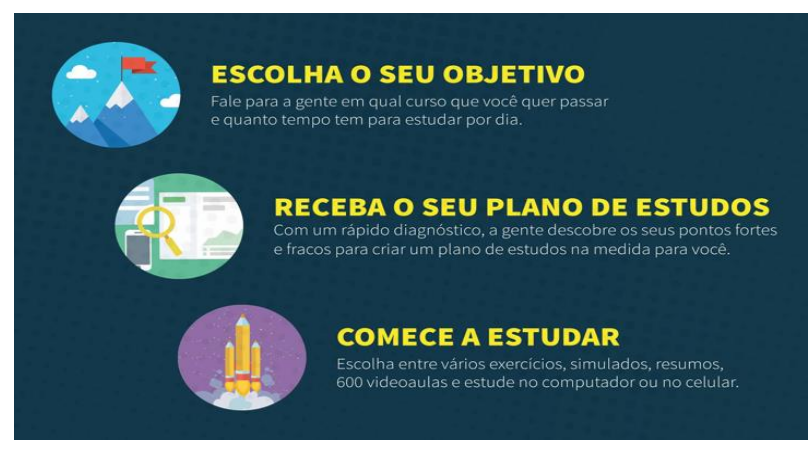

Figura 3 - Trajeto para a definição do plano de estudo personalizado.

Fonte: www.horadoenem.mec.gov.br. Acesso em 27 nov 2016.

Uma vez cadastrado o aluno possui uma série de ferramentas que não estão disponíveis para outros usuários. Ele pode selecionar a instituição e curso do seu interesse e ver que nota do Enem precisaria tirar para ser aprovado. Pode também testar os conhecimentos para avaliar o quão distante está em relação aos objetivos.

\section{Questões resolvidas (X da Questão)}

O portal também disponibiliza em vídeo questões de exames anteriores resolvidas e comentadas por professores e especialistas, como mostra a figura 4:

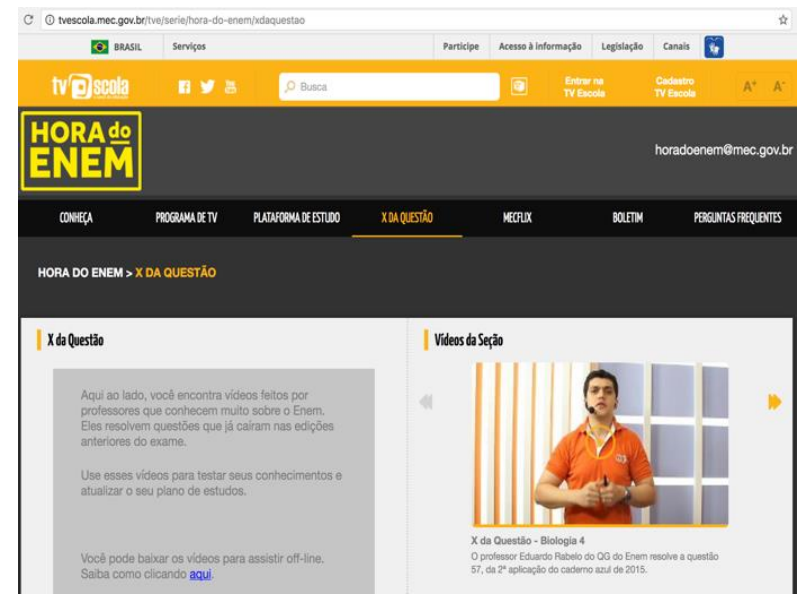

Figura 4 - página do portal "X da Questão", com questões resolvidas de exames anteriores.

Fonte: www.horadoenem.mec.gov.br. Acesso em 27 nov 2016. 
$16^{\circ}$ Ergodesign - Congresso Internacional de Ergonomia e Usabilidade de Interfaces Humano Tecnológica: Produto, Informações Ambientes Construídos e Transporte

$16^{\circ}$ USIHC - Congresso Internacional de Ergonomia e Usabilidade de Interfaces Humano Computador

CINAHPA | 2017 - Congresso Internacional de Ambientes Hipermídia para Aprendizagem.

\section{Aplicativo e plataforma MECFlix}

O MECFlix é a plataforma online de vídeo-aulas preparatórias para o ENEM oferecida pelo Ministério da Educação e seus parceiros, integrada ao Hora do Enem.

Qualquer usuário poderá visualizar todos os vídeos que a plataforma oferece. Após realizar cadastro, o usuário também pode interagir com as ferramentas que a plataforma oferece como anotações em vídeos, criação de playlists compartilháveis e comentários.

O número de vídeos no lançamento da plataforma (abril de 2016), foi de 1900, e há o abastecimento de novos vídeos produzidos pelos parceiros do MEC (como a Geekie Game, Descomplica, FGV, Kroton e QG do Enem, por exemplo). A figura 5 mostra a tela inicial do MEcFlix:
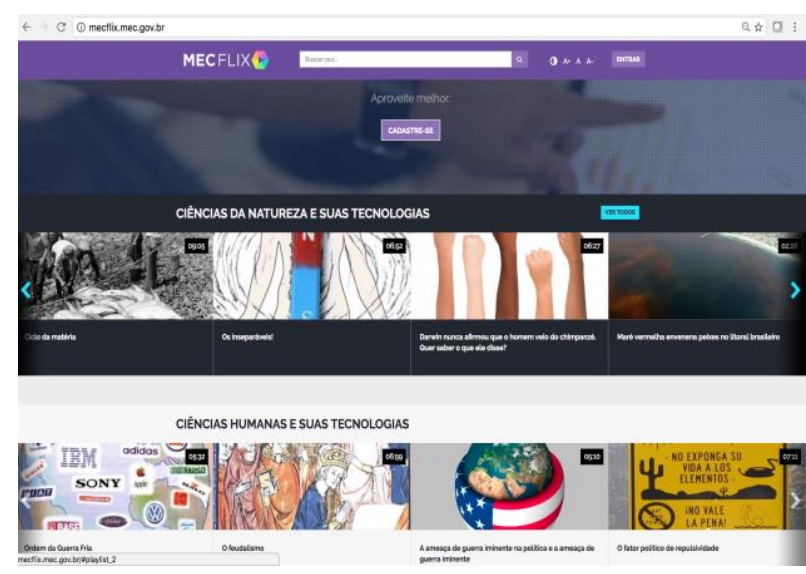

Figura 5 - Tela inicial do MECFlix.

Fonte: www.horadoenem.mec.gov.br. Acesso em 27 nov 2016.

\section{Boletim de noticias}

O Boletim com dicas do Enem tem caráter informativo e uma duração de até 2 (dois) minutos. Informará sobre todo e qualquer aspecto envolvendo o Enem, desde a sua organização e aplicação, até os aspectos de conteúdo das questões e orientações de todo tipo voltadas para os estudantes, como mostra a figura 6 :

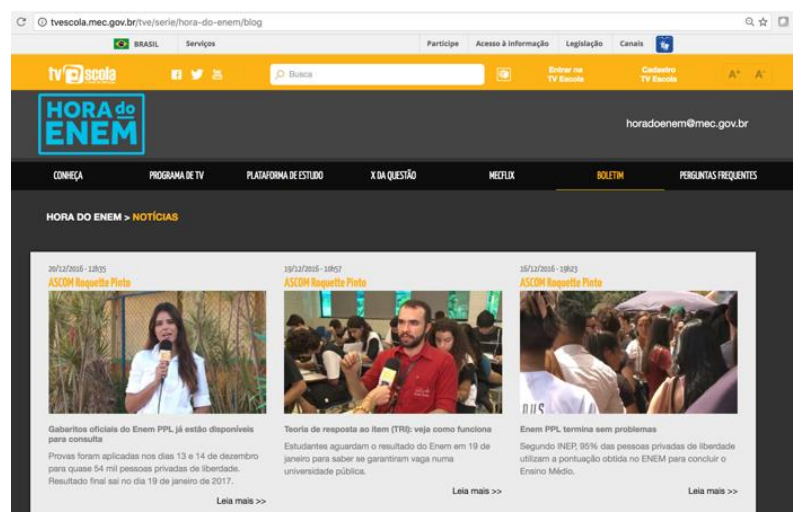

Figura 6 - Tela inicial do MECFlix.

Fonte: www.horadoenem.mec.gov.br. Acesso em 27 nov 2016.

Ao apresentar as múltiplas possibilidades e as diferentes mídias que o portal disponibiliza, este trabalho busca mapear quais são as estruturas do projeto que são (ou podem ser) exploradas de acordo com as narrativas transmídia, com a intenção de promover o processo de imersão dos alunos aos conteúdos, estabelecer pontes narrativas entre os conteúdos e promover a construção e compartilhamento dos conteúdos por parte dos alunos cadastrados na plataforma, trazendo aos processos de ensino-aprendizagem presentes no projeto um caráter dinâmico e distinto dos padrões tradicionais de ensino.

\section{Método}

Para realizar a análise das características transmídia do projeto "Hora do Enem" este trabalho se debruça sobre o Close Reading, método desenvolvido nos campos da teoria literária no final dos anos 1930 e 1940. Segundo [Inman, 2003], o método foi formulado por John Crowe Ransom e outros "novos críticos" e buscava analisar textos se afastando dos contextos sociais, históricos e humanos em que uma obra era produzida e interpretada. A objetividade defendida pelos "novos críticos", especialmente as propostas de [Wimsatt Jr \& Beardsley, 1949] - que tinham como característica principal não considerar em um texto a relação com o leitor e suas sensações foi interpretada como não eficaz algumas décadas depois. 


\section{$16^{\circ}$ \\ ERGODESIGN USIHC CINAHPA}

Para [Tanenbaum, 2015], "essa formulação pode ser considerada um tanto quanto extrema. Ao tentar isolar o texto de suas causas e efeitos de forma estridente, os novos críticos criaram um vácuo crítico artificial em que a leitura de um texto, agora podia estar isolada do leitor".

O estudioso cita o exposto por [McGuire, 1973], enfatizando que a individualidade do leitor é essencial para a experiência da leitura. Assim, é essa individualidade que faz com que cada pessoa possa descobrir, significar e ressignificar o texto como uma experiência única. Mas se a individualidade do leitor pauta o processo de significação textual, então não é possível fazer uma leitura crítica de uma obra?

Segundo [Tanenbaum, 2015], atualmente é possível analisar um texto - inclusive um texto construído nas mídias digitais - utilizando lentes analíticas para realizar uma leitura crítica. Neste trabalho, por meio do método Close Reading, podemos utilizar recursos e estratégias das próprias práticas literárias, buscando pontos de análise objetivos e, como apontado por [McGuire, 1973], encontrar um equilíbrio entre a subjetividade e os significados do texto. Para tanto é necessário conduzir a análise por meio da lentes analíticas, partindo de pressupostos de análise que devem preservar a integridade do trabalho analisado, como também permitir a construção de ideias analíticas aplicadas a este contexto.

Assim, a construção do enfoque adotado no Close Reading se dá a partir da escolha de lente analíticas, buscando elementos objetivos de construção do texto.

\section{Lentes analíticas}

Para este trabalho, a análise do projeto "Hora do Enem", busca a desconstrução textual da arquitetura de conteúdos nas diferentes mídias apresentadas, verificando a ocorrência de estratégias transmídia na educação e como elas têm sido utilizadas para que os processos de ensino aprendizagem possam ser dinamizados e construídos sob uma ótica distinta do processo de educação tradicional. $16^{\circ}$ Ergodesign - Congresso Internacional de Ergonomia e Usabilidade de Interfaces Humano Tecnológica: Produto, Informações Ambientes Construídos e Transporte

$16^{\circ}$ USIHC - Congresso Internacional de Ergonomia e Usabilidade de Interfaces Humano Computador

CINAHPA | 2017 - Congresso Internacional de Ambientes Hipermídia para Aprendizagem.
Para tanto, buscou-se mapear as suas características transmídia, como:

1. Quais são as pontes narrativas [Jenkins, 2004] presentes no projeto; 2 . Verificar os diferentes Storyworlds [Bizzocchi, 2014];

3. Mapear a amplitude de conteúdos e informações extras, por meio de pedaços de informação chamados de sementes e; 4 . Verificar quais são os potencias de projeções que vão além da narrativa.

Em relação aos itens 3 e 4, [Jenkins, 2012], em seu artigo "Lendo criticamente e lendo criativamente", identifica alguns elementos básicos que inspiram intervenções de fãs dentro das narrativas transmidiáticas:

- Sementes: pedaços de informação introduzidos na narrativa para indicar um mundo maior que não é completamente desenvolvido na própria história. As sementes tipicamente nos afastam do enredo central e introduzem possibilidades de histórias a explorar. Em relação as sementes, temos no processo educacional o estímulo a um aluno que pretende se aprofundar em um tema.

- Potenciais: projeções sobre o que poderia ter acontecido além dos limites da narrativa. Muitos leitores terminam um romance e se encontram querendo especular sobre o que acontece em seguida. Quais são as consequências do que foi apresentado em determinado curso se associadas ao "mundo real"?

Com o mapeamento dos itens acima, pode-se verificar como recursos utilizados em projetos transmídias podem beneficiar o fluxo da informação em projetos educativos e mobilizar a imersão dos alunos, mobilizando a construção do conhecimento.

\section{Decomposição do artefato}

$\mathrm{O}$ artefato deve ser decomposto de acordo com cada uma das "plataformas" apresentadas anteriormente (programa de TV; plataforma de estudo; questões resolvidas; plataforma de vídeos MECFlix e boletim de notícias), buscando suas características transmídia (pontes narrativas, 


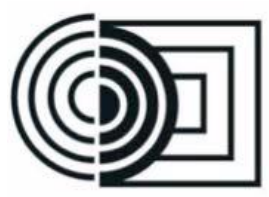

micronarrativas, sementes, buracos e potenciais aspectos de interação e compartilhamento).

\section{Resultados e considerações}

$\mathrm{O}$ enquadramento do projeto se associa às características das narrativas transmídia, no qual podemos tomar os conteúdos de estudo como um eixo central (ou meta-narrativa), formado pelos conteúdos que serão cobrados na prova do Exame Nacional do Ensino Médio - Enem); e que, se desdobram por meio do que Jenkins (2004) e Bizzocchi (2014), denominam de micronarrativas no caso do projeto aqui estudado, podemos considerar micronarrativas, cada desdobramento de conteúdo inserido na ementa das disciplinas (números complexos, geometria analítica, trigonometria etc, na matemática, por exemplo).

Ancorados por meio das narrativas transmídia, os diferentes conteúdos podem ser considerados parte de um storyworld (de cada disciplina ou grande área) que se fraciona em micronarrativas - que podem ser relacionadas (diretamente pelo aluno ou, em pontes narrativas criadas pelos próprios condutores das narrativas - o programa de TV muitas vezes faz essas relações; a plataforma de exercícios nos conteúdos e os próprios exercícios muitas vezes reforçam outros temas apresentados em outras aulas). Em uma análise mais aprofundada, tomemos cada uma das "plataformas" disponíveis no portal:

\section{Programa de TV}

O programa de TV é seriado e cada episódio apresenta uma das grandes áreas do Enem. Para este trabalho, foi assistido o programa 1-

Logaritmo, Equação da Circunferência e Música. A figura 7 mostra o acesso ao programa no portal "Hora do Enem" $16^{\circ}$ Ergodesign - Congresso Internacional de Ergonomia e Usabilidade de Interfaces Humano Tecnológica: Produto, Informações Ambientes Construídos e Transporte

$16^{\circ}$ USIHC - Congresso Internacional de Ergonomia e Usabilidade de Interfaces Humano Computador

CINAHPA | 2017 - Congresso Internacional de Ambientes Hipermídia para Aprendizagem.

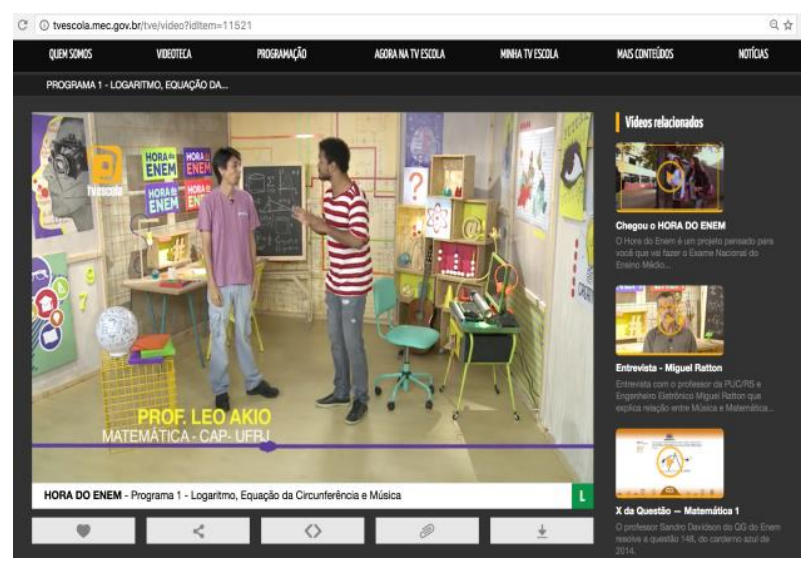

Figura 7 - Programa de TV

Fonte: www.horadoenem.mec.gov.br. Acesso em 27 nov 2016.

Tomemos cada uma das lentes analíticas propostas anteriormente para realizar a análise:

\section{1. pontes-narrativas e micronarrativas}

O programa recebe um professor especialista que mostra teorias sobre equação de circunferência e logarítimos, que são permeadas pela resolução de exercícios por outros professores. O convidado (professor especialista), comenta as soluções e cria algumas pontes narrativas para que o aluno possa explorar "novas narrativas". Em dois momentos do vídeo ele indica links de sites para aprofundamento no conteúdo, alguns canais no Youtube, e um livro, para que os alunos possam acessar novos conteúdos.

Essas pontes são fundamentais para o processo de construção dos conhecimentos, já que exibe outras fontes de informação e, estimulando o processo de fluxo a novas micronarrativas (já que o conteúdo é um aprofundamento da macro-narrativa presente no programa).

\section{Storyworlds}

Ao direcionar o aluno para novos conteúdos (por meio dos links de aprofundamento), como essas narrativas tem outra estética (que em geral não é a mesma do programa de TV), o aluno adentra em novos storyworlds. 
$16^{\circ}$ Ergodesign - Congresso Internacional de Ergonomia e Usabilidade de Interfaces Humano Tecnológica: Produto, Informações Ambientes Construídos e Transporte

$16^{\circ}$ USIHC - Congresso Internacional de Ergonomia e Usabilidade de Interfaces Humano Computador

CINAHPA | 2017 - Congresso Internacional de Ambientes Hipermídia para Aprendizagem.

\section{Sementes}

Um outro especialista que vai ao programa, mostra a possibilidade de relacionar as nota musicais com o teorema de Pitágoras, introduzindo pedaços de informação que indicam que um mundo maior pode ser acessado a partir do que foi apresentado (no caso, a relação da matemática com a música), marcando o conceito que são os pedaços de informação introduzidos na narrativa para indicar um mundo maior que não é completamente desenvolvido na própria história.

\section{Potenciais}

No caso dos potenciais, que projetam possibilidades além dos limites da narrativa, aqui pode-se pensar que os links apresentados podem ser um estímulo para adentrar a novos conhecimentos e que, ao aceitar ou abdicar da proposta, há uma projeção direta na condução do processo de acesso e conhecimento do que a metanarrativa pode oferecer.

\section{Plataforma de Estudo}

A plataforma de estudo permite o aluno acessar conteúdos de estudo, fazer exercícios, simulados e traçar seu plano de estudos de acordo com o desempenho (mapeando pontos de qualificação e possíveis pontos de reforço em cada área temática).

Um destaque é que todos os conteúdos disponíveis, permitem "construções narrativas" definidas pelo próprio aluno. A figura 8 mostra uma aula sobre logarítimos e funções logarítimicas:
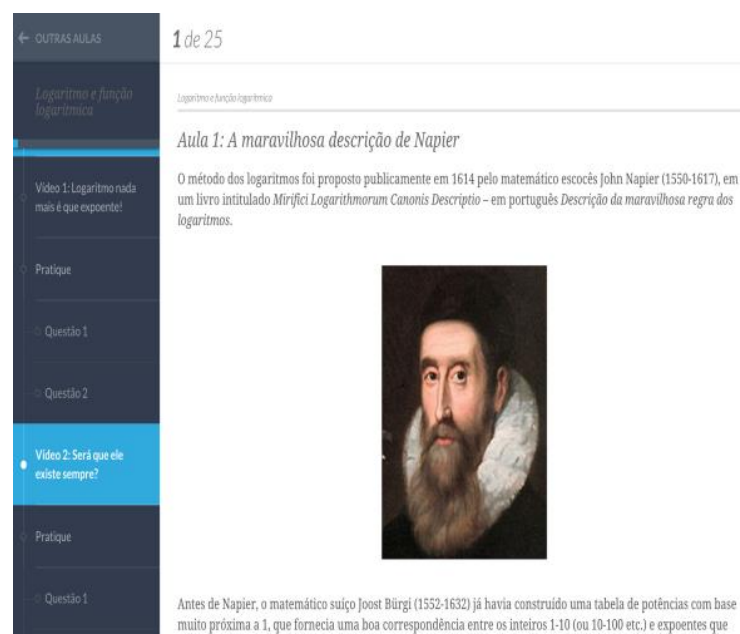

Figura 8 - plataforma de estudos com a aula logarítmos e funções logarítmicas.

Fonte: www.horadoenem.mec.gov.br. Acesso em 27 nov 2016.

Note que na barra lateral em cinza, temos o trajeto que a aula deve percorrer (vídeo 1, pratique, questão 1 , questão 2 , vídeo 2 etc).

Como o aluno tem autonomia para acessar qualquer campo da trilha (vídeo 1, pratique, questão 1 , questão 2 , vídeo 2 etc), ele acaba sendo o próprio agente construtor de sua narrativa de conteúdos (como em um filme em que se escolhe as cenas). Tomemos então os pontos de análise:

1. pontes-narrativas e micronarrativas

Ao permitir que o aluno possa acessar qualquer parte da trilha de conhecimento, a meta-narrativa passa a ser o tema central da aula (logarítmos e funções logarítmicas) e, ao escolher se vai acessar ou deixar de acessar vídeos, exercícios, conteúdos, o aluno é quem escolhe como irá construir e acessar suas pontes e micronarrativas.

\section{Storyworlds}

Em relação ao Storyworld, apenas se apresenta o relativo ao do conteúdo que está disponível na plataforma de estudo.

\section{Sementes}

As semente nesse caso não são aparentes, mas cada conteúdo pode trazer a possibilidade de se explorar esse quesito. No caso do conteúdo apresentado não foi possível localizar sementes de conteúdo. 
$16^{\circ}$ Ergodesign - Congresso Internacional de Ergonomia e Usabilidade de Interfaces Humano Tecnológica: Produto, Informações Ambientes Construídos e Transporte

$16^{\circ}$ USIHC - Congresso Internacional de Ergonomia e Usabilidade de Interfaces Humano Computador

CINAHPA | 2017 - Congresso Internacional de Ambientes Hipermídia para Aprendizagem.

\section{Potenciais}

No caso de potenciais, os exercícios, simulados e metas podem trazer potenciais de se explorar "novos mundos". Ao não conseguir ir bem em um simulado, o aluno pode adentrar os outros conteúdos da plataforma ou, ir buscar em outros locais possibilidades de acessar novos conteúdos para mobilizar o aprendizado.

\section{Questões resolvidas (“X da questão”)}

Ao acessar os conteúdos, temos inúmeras questões, porém, elas são apenas a replicação das questões que são apresentadas no programa de TV. Assim, optou-se por não realizar a análise, já que elas não são novas narrativas, mas apenas a replicação do que já foi abordado.

\section{MECFlix}

O MecFlix permite que o aluno acesse os temas específicos de cada área, escolhendo uma parte da ementa que o Enem cobra na prova. Assim, diferentemente do programa de TV, ele se dedica a pequenas micronarrativas que fazem parte das grandes áreas temáticas. Vejamos na figura 9 uma das 22 possibilidade ao se utilizar o tema que seguimos desde o início desse trabalho (logarítimos) como palavra-chave para a pesquisa no MECFlix:

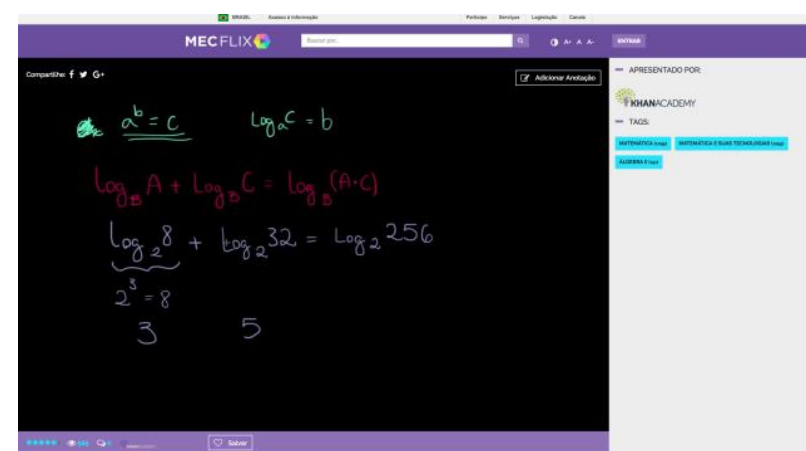

Figura 8 - plataforma de estudos com a aula logarítmos e funções logarítmicas.

Fonte: www.horadoenem.mec.gov.br. Acesso em 27 nov 2016.
Como foi explicitado anteriormente, o Mecflix trabalha com micronarrativas, fechadas por temas específicos ligados a eixos centrais. Assim, como ele já atua com micronarrativas, em storyworlds distintos e, não tem gatilhos direcionais para promover sementes e potenciais.

\section{Boletim de notícias}

O Boletim leva aos alunos notícias atualizadas do Enem e dicas de caráter informativo, com uma duração de até 2 (dois) minutos. O boletim, em relação às narrativas de conteúdos de aprendizagem não contém aulas ou temas específicos, porém, em relação aos processos de organização de estudos, estímulos e pontes narrativas com diversos outros temas, é um agente que mobiliza diversos gatilhos.

\section{Pontes narrativas e micronarrativas}

Cada reportagem parte de um tema específico de abordagem e gera inúmeras pontes narrativas (hora citando exercícios, os programas de TV, simulados da plataforma, dentre outros) e sempre trazendo temas plurais que podem ser quebrados em narrativas aprofundadas.

\section{Storyworlds}

Em relação ao Storyworld, as reportagens apresentam elementos comuns (espaços físicos como escolas, espaços de estudo e salas de aula; personagens comuns - educadores e alunos; e o tema central - o Enem), porém, cada matéria apresenta "novos mundos", novas possibilidades de estudo e dos conteúdos.

\section{Sementes}

Ao apresentar histórias de pessoas reais, criam-se gatilhos de informação que podem estimular o aluno a buscar outras possibilidades em relação aos estudos, a plataforma, simulados, mostrando outras possibilidades de se desenvolver as estratégias de estud.

\section{Potenciais}




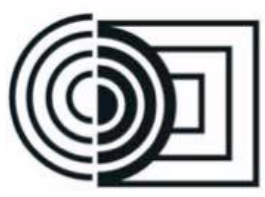

$16^{\circ}$ Ergodesign - Congresso Internacional de Ergonomia e Usabilidade de Interfaces Humano Tecnológica: Produto, Informações Ambientes Construídos e Transporte

$16^{\circ}$ USIHC - Congresso Internacional de Ergonomia e Usabilidade de Interfaces Humano Computador

CINAHPA | 2017 - Congresso Internacional de Ambientes Hipermídia para Aprendizagem.
Ao propor em mostrar como o mundo real lida com o processo do exame, o boletim mostra casos reais, estimulando e permitindo que os alunos se inspirem e associem o que é apresentado com suas realidades. Um exemplo foi a solicitação dos alunos para prorrogar o prazo de inscrição e realização de um simulado, e que, após ser divulgado no boletim, mobilizou a prorrogação do prazo. A figura 9 mostra a notícia:

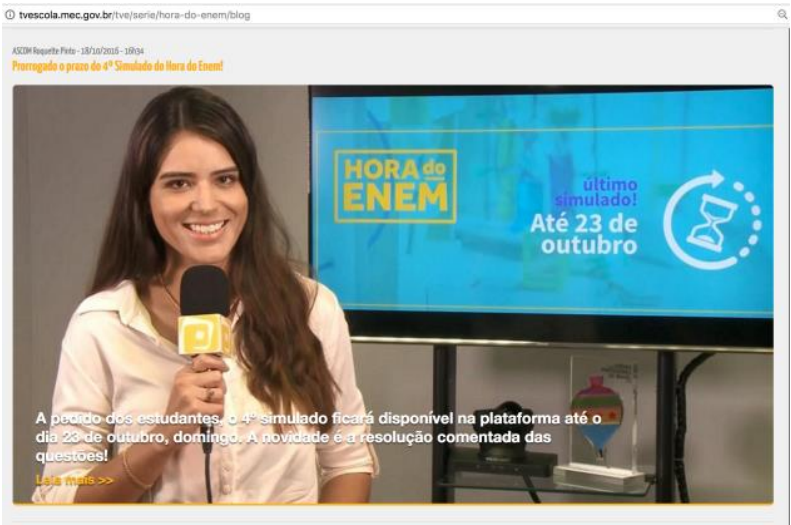

Figura 9- Boletim de notícias

Fonte: http://tvescola.mec.gov.br/tve/serie/hora-doenem/blog Acesso em 05 dez 2016.

\section{Conclusão}

Este trabalho buscou apresentar algumas das características de como as TICs trouxeram mudanças em diversos paradigmas e estão modificando também o processo da educação, com os conceitos de Sociedade do Conhecimento [Castells, 1999] e Sociedade da Informação [Levy, 1999] e a mudança nos modelos e processos educacionais mediada

A partir dos conceitos de pontes narrativas e micronarrativas; Storyworld [Bizzocchi, 2012]; e as propostas de Jenkins [2011] de possibilidades de maior imersão dos usuários nas narrativas, com a definição de estratégias chamadas pelo autor de sementes e potenciais, foi feita a análise de cada uma das "plataformas" de mídia disponibilizadas no portal "Hora do Enem".
Constata-se que, apesar do projeto não ter sido desenhado pensando nas estratégias aqui apresentadas, pudemos verificar como é possível utilizar estratégias transmídia em conteúdos educativos na internet. Ao analisar o portal multiplataforma "Hora do Enem", foi possível localizar em diversas sessões do projeto, fluxos narrativos que conduzem o aluno a uma imersão aprofundada.

Outro ponto importante é que conteúdos multiplataformas podem ser desenvolvidos de maneira a otimizar a criação de sementes e potenciais, promovendo uma participação maior dos alunos, estimulando sua interação e o processo de cocriação.

Conclui-se que as equipes envolvidas em projetos para a produção de cursos on-line (educadores, desenvolvedores, pedagogos, programadores, designers) podem utilizar-se do processo de desenvolvimento transmídia para elaborar fluxos e pontes narrativas de conteúdos educacionais

Para trabalhos futuros sugerimos uma análise dos conteúdos apresentados nas plataformas do "Hora do Enem" em relação ao processo narrativo, e/ou, os potenciais de mobilização de "novas narrativas de conhecimento - vídeos, textos, aulas etc", construídas pelos próprios participantes do projeto.

\section{Referências Bibliográficas}

BERNHEIN, C, T. Desafios da universidade na sociedade do conhecimento: cinco anos depois da conferência mundial sobre educação superior / Carlos Tünnermann Bernheim e Marilena de Souza Chauí. - Brasília : UNESCO, 2008.

BIZZOCHI, J., \& TANENBAUM, J. Mass Effect 2: A Case Study in the Design of Game

Narrative. Bulletin of Science Technology Society, (2012).

CASTELLS, M. A Era da informação: economia, sociedade e cultura. São Paulo, Paz e Terra, 1999. $3 \mathrm{v}$. 


\section{$16^{\circ}$ \\ ERGODESIGN USIHC CINAHPA}

$16^{\circ}$ Ergodesign - Congresso Internacional de Ergonomia e Usabilidade de Interfaces Humano Tecnológica: Produto, Informações Ambientes Construídos e Transporte

$16^{\circ}$ USIHC - Congresso Internacional de Ergonomia e Usabilidade de Interfaces Humano Computador

CINAHPA | 2017 - Congresso Internacional de Ambientes Hipermídia para Aprendizagem.

GALLO, P. \& COELHO, M.G.P. Aquisiçãa dos letramentos necessários à cultura da convergência: a narrativa transmídia na escola. (2011) Disponível em: http://repositorio.unp.br/index.php/quipus/artic le/view/59. Acesso em: 03 jun. 2016

GERBASI, C. Desafios na construção de uma estética audiovisual para educação à distância (EAD). In revista Logos 24: cinema, imagens e imaginário. Ano 13, $1^{\circ}$ semestre 2006.

INMAN, J. A. (2003). Electronic Texts and the Concept of Close Reading: a Cyborg Anthroplogist's Perspective. In J. R. Walker \& O. O. Oviedo (Eds.), TnT: Texts and Technoloy.

Cresskill, New Jersey: Hampton Press, Inc.

JENKINS, H. Cultura da convergência. São Paulo, Editora Aleph, 2008.

Lendo criticamente e lendo criativamente. In: Revista Matrizes, ECA/USP, São Paulo. V. 6, N. 1-2 (2012).Disponível em http://www.matrizes.usp.br/index.php/matrizes /article/viewFile/375/pdf. Acesso em 15 jun 2016.

Design as Narrative Architecture. First Person: New media as story, perfomance, and game/ edite by Noah Wardrip and Pat Harrigan. The MIT Press, 2004.

KENSKI, Vani. M. Tecnologia e ensino presencial e a distância. Campinas, SP: Papirus, 2003.

MCGUIRE, R. L. (1973). Passionate Attention: An Introduction to Literary Study. New York, NY: W.W. Norton \& Company.

TANENBAUM, J. Identity Transformation and Agency in Digital Narratives and Story Based Games. SIMON FRASER UNIVERSITY Spring 2015. 